\title{
A New Method for Curriculum Design Based on Hall 3D Structure
}

\author{
Jing Guo ${ }^{1, a}$, Ying Deng ${ }^{2, b, *}$ \\ ${ }^{1}$ College of Electronics and Information Engineering, Southwest University, Chongqing, China \\ 2 Chongqing College of Humanities, Science and Technology Chongqing, Chongqing, China \\ apoem24@163.com, bgjl0hr@163.com
}

Keywords: Curricular design, Multi-dimensional space, A.D Hall three-dimension, ABET's criteria

\begin{abstract}
Accreditation Board for Engineering and Technology (ABET) suggested new various criteria for accrediting engineering programs at the university level in 2016. According to ABET's suggestions, this paper discusses the Multi-dimensional principles of curriculum organization and employs A.D Hall three-dimension model to design three different levels methodology spaces to explain which items are including and how to put these into effect in curriculum system for concretely performing ABET's criteria. These methodology spaces are intended to offer a clear, feasible and operational approach to assist our faculty in developing the visualization method for achieving the ABET's criteria, and to foster the systematic pursuit of improvement in the quality of innovative engineer education.
\end{abstract}

\section{Introduction}

The word curriculum derives from the Latin verb "currere", meaning "racing chariot" or "race track" [1]. This implies that functions of a curriculum are to provide a design which enables learning to take place. According to Edward S.E, Curriculum refers to the means and materials with which students will interact for the purpose of achieving identified educational outcomes [2].

Many papers discussed the key factors involved in curriculum development and described approaches to curriculum design. John Gorgone proposed a model curriculum for undergraduate degree programs in Information Systems [3]. Farid J. S investigated the existence and prevalence of undergraduate courses devoted to the study of building information modeling and to discover the constraints on these programs [4]. Xu bin adopted the theories of education and systems engineering, and employed both qualitative and quantitative approaches to design the construction of undergraduate curriculum system for innovative engineering education [5]. Baumgartner described how the learning outcomes defined at the level of the program and competencies defined at the course level are practically used in the process of the course design and delivery [6]. Jim Gleeson critically considers the European Credit Transfer System (ECTS) from the perspectives of outcomes-based education and the alternative process model of curriculum design [7]. Tara Fenwick discussed the relations between knowledge, curriculum, teaching and learning, assessment and the understandings that Student develop through their engagement with higher education programmer [8]. Gerlach Christina conducted a prospective questionnaire-based cohort study with a pre-post design to evaluate the effects of the Mainz Undergraduate palliative care education on students' self-confidence regarding important domains in palliative care [9]. Qing-Hua Deng discussed the reform orientation of undergraduate curriculum of digital media arts according to the characteristics of talents, development needs of industry and education objectives [10]. Gary M. Muir described key factors to consider in the planning and implementation of assessment for an undergraduate neuroscience program [11].

In 2016, Accreditation Board for Engineering and Technology (ABET) suggested various criteria for accrediting engineering programs at the university level during the 2016-2017 [12]. These criteria are broad statements that describe what graduates are expected to attain within a few years after graduation. According to these suggestions, this paper discusses the Multi-dimensional principles of curriculum organization and employs A.D Hall three-dimension model to design a feasible 
three-dimension methodology for concretely performing ABET's criteria. The model is intended to assure quality and to foster the systematic pursuit of improvement in the quality of engineering education that satisfies the needs of constituencies in a dynamic and competitive environment. The approach reflects the new design approach characterized by a different levels of methodology underpinned by a clear understanding of the critical aspects of effective curricula supported through the new design and ABET's criteria.

\section{Three-Dimension Methodology of Student Outcomes}

A set of procedures which provide the means for solving certain problems is known as a methodology. For carrying out the ABET's criteria we need a methodology to explain which items are including and how to put these into effect in innovative engineer education. ABET's criteria have documented student outcomes that prepare graduates to attain the program educational objectives. We detail these student outcomes as follows [12].

(a) An ability to apply knowledge of mathematics, science, and engineering

(b) An ability to design and conduct experiments, as well as to analyze and interpret data

(c) An ability to design a system, component, or process to meet desired needs within realistic constraints such as economic, environmental, social, political, ethical, health and safety, manufacturability, and sustainability

(d) An ability to function on multidisciplinary teams

(e) An ability to identify, formulate, and solve engineering problems

(f) An understanding of professional and ethical responsibility

(g) An ability to communicate effectively

(h) The broad education necessary to understand the impact of engineering solutions in a global, economic, environmental, and societal context

(i) A recognition of the need for, and an ability to engage in life-long learning

(j) A knowledge of contemporary issues

(k) An ability to use the techniques, skills, and modern engineering tools necessary for engineering practice

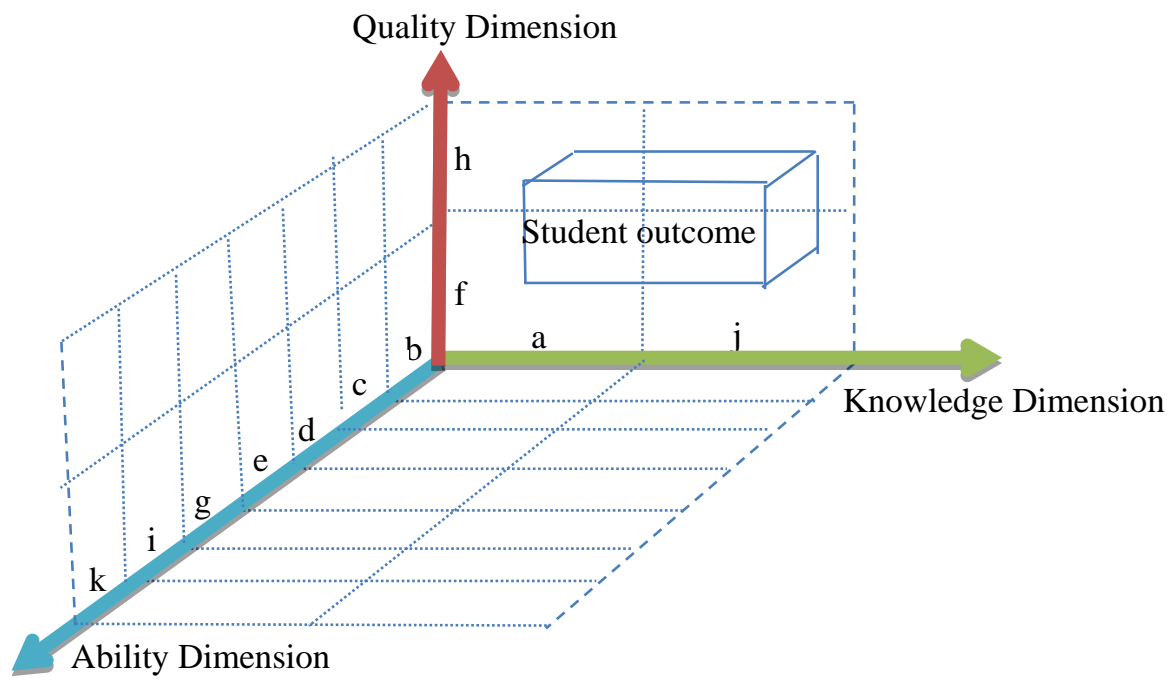

Fig. 1. Methodology space for student outcomes kernel.

Student outcomes (a) through (k) plus any additional outcomes that may be articulated by the program could constitute an outcome methodology. Arthur D. Hall, in 1969, published a comprehensive three-dimensional methodology for performing architectural analyses of complex systems of systems using process odeling[13]. What steps might be taken at the program and individual course levels to raise the level of achievement of the outcomes? Based on this three-dimensional idea, we could sum up these student outcomes in three-dimensional Euclidean 
space by mans of three coordinates, which are labeled knowledge dimension, quality dimension and ability dimension. Fig. 1 is images of the above-mentioned space.

Fig. 1 is an adaptation of Hall's representation of the three-dimensions of student outcomes. The knowledge dimension includes student outcomes (a) and (j) that refers to knowledge of language, mathematics, science, and engineering. The quality dimension includes student outcomes (h) and (f) that refers to professional, society and ethical responsibility. The ability dimension includes student outcomes (b), (c), (d), (e), (g), (i) and (k) that refers to specialized ability from the various engineering problems. This methodology space describes what students are expected to know and be able to do by the time of graduation.

\section{Three-Dimension Methodology of Curriculum System}

Curriculum system constitutes the core of the teaching-learning process. For every student outcome in Fig.1, we could further map it in another three-dimensional Euclidean space, as shown in Fig.2. We outline executable map that address curriculum system how to achieve the student outcomes and on the research that supports their effectiveness. These fundamental dimensions for curriculum system are as follows.

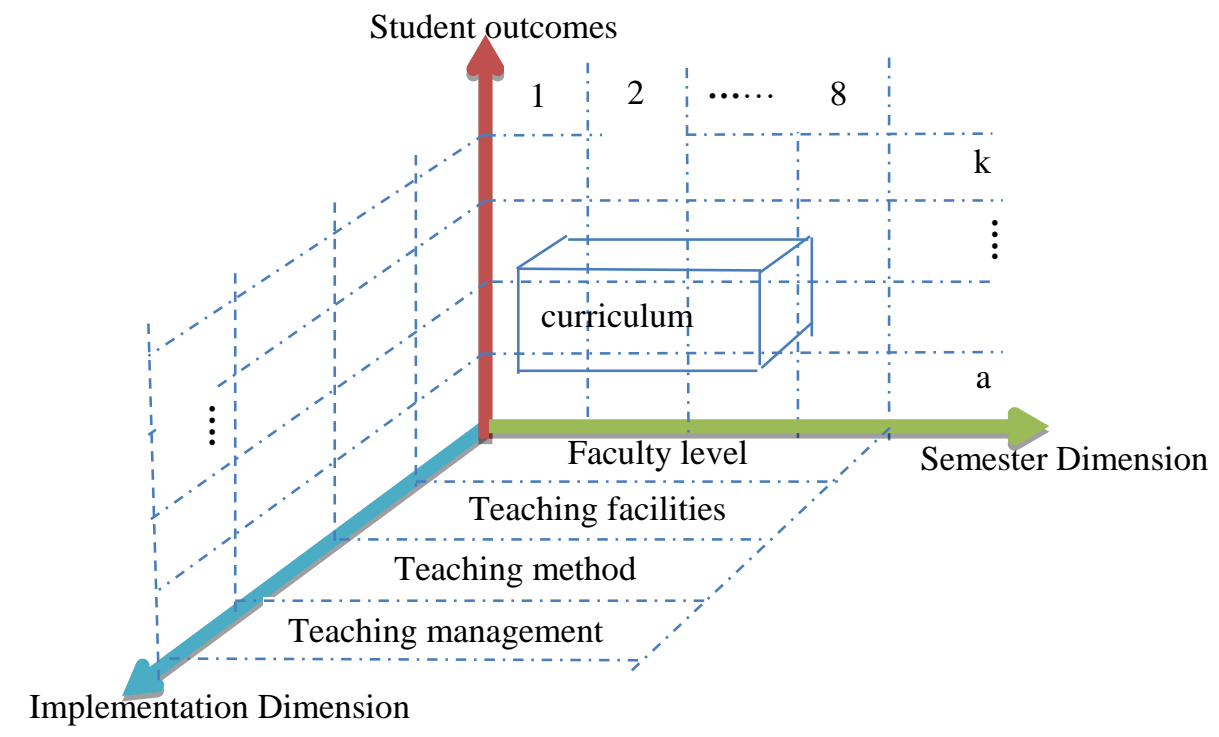

Fig..2. Methodology space for curriculum system

(1) The first is semester dimension which is altogether eight semesters depicting a sequence of activities in the life of four-year university education.

(2) The second is student outcome dimension which includes student outcomes (a) through (k) that relate to the quality, knowledge, and ability that students acquire as they progress through the university education.

(3) The third dimension models a scheme solving problem, which includes faculty level, teaching facilities, teaching method and teaching management that refer to specialized teaching scheme for completing certain curriculum. This scheme must ensure that the implementation dimension devotes adequate resources and time to each student outcome, consistent with the objectives of the institution. The student outcomes are an important strategy to assist the students focus on what they need to do in the learning process. "If you know exactly what your objectives are, it is easier to achieve them". The curriculum system must have clearly stated these student outcomes. These form the basis of deciding on the content, executable methods and evaluation procedures. They are a very important component of curriculum word curriculum derives from the Latin verb "currere", meaning "racing chariot" or "race track" [1]. This implies that functions of a curriculum are to provide a design which enables learning to take place. According to Edward S.E, Curriculum refers to the means and materials with which students will interact for the purpose of achieving identified educational outcomes [2]. 


\section{Three-Dimension Methodology of a Specific Course}

Each curriculum design is fundamental to the curriculum development process and other aspects of curriculum system. It is therefore important to structure and visualize every curriculum design. One of the easy ways to structure and visualize curriculum design is through further specifying every course in three-dimensional curriculum system space, as shown in Fig.3.

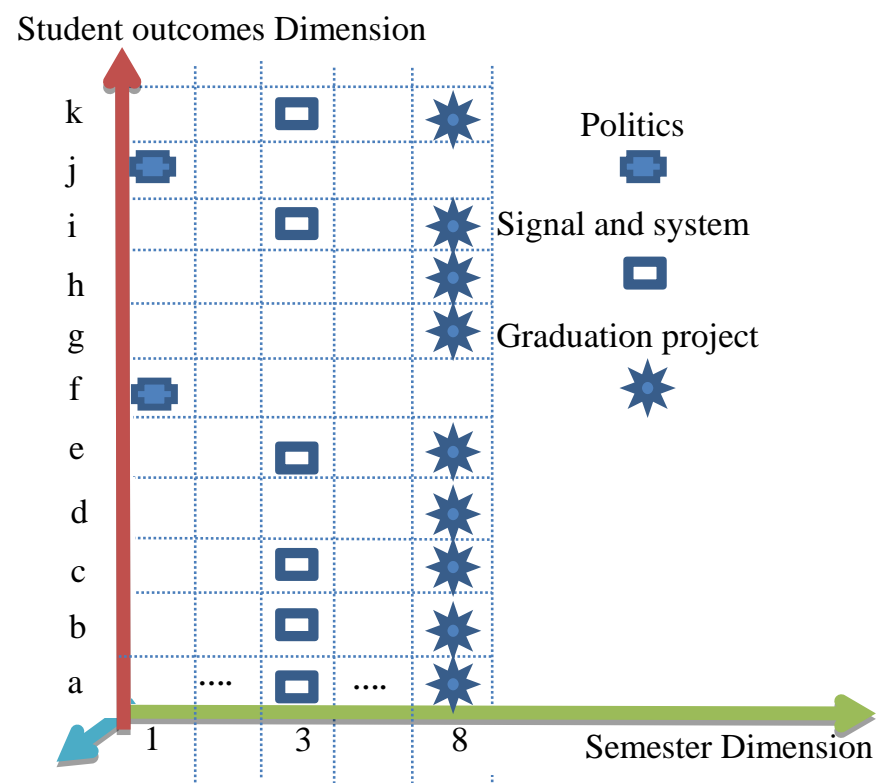

Implementation Dimension

Fig. 3. Methodology space for individual course

We take communication engineering degree for example, and only itemize three courses, such as POLITICS, SIGNAL AND SYSTEM, and GRADUATION PROJECT for simplicity's sake. As seen in Fig. 3, POLITICS is arranged in the first semester and could accomplish the student outcome (i) and (f). SIGNAL AND SYSTEM is fixed in the third semester and could achieve the student outcome (a), (b), (c), (e), (i) and (k). GRADUATION PROJECT is planned in the eighth semester and could achieve the student outcome (a), (b), (c), (d), (e), (g), (h), (i) and (k).

Creating a course to achieve specified student outcomes requires effort in planning, and assessment and evaluation. For each course, such as SIGNAL AND SYSTEM, we could draw up its implementation dimension methodology space, as shown in Fig.4.

The implementation space must are detailed stipulated, with the key questions that need to be answered presented, including 'What' 'Why' and 'How' questions. And, the contents of the implementation space may dynamically be set up according to the actual situation. For SIGNAL AND SYSTEM, we temporarily set four items: faculty level, teaching facilities, teaching method and teaching management. The detailed contents could be seen in Fig.4.

\section{Conclusion}

The main objective of this paper is to develop a new approach to curriculum design to feasibly perform ABET's 2016-2017 criteria. The main reason for developing this approach is that we need an operational and simple measure to assist our faculty in developing the visualization method for achieving the ABET's criteria. The approach includes three different levels methodology: student outcomes-level, curriculum system-level, and course-level. There methodology may allow our faculty to ascertain every step and every aspect of ABET's criteria and to assure quality and to foster the systematic pursuit of improvement in the quality of education activities that satisfies the needs of innovative teaching in a dynamic and vigor environment. If faculty members structure their course syllabi, learning objectives, and teaching methods to address the ABET's criteria, the result is a coherent curriculum in which all courses have well-defined and interconnected roles in achieving the 
educational objectives. The approach must be monitored to foster success in attaining student outcomes, thereby enabling graduates to attain program educational objectives.

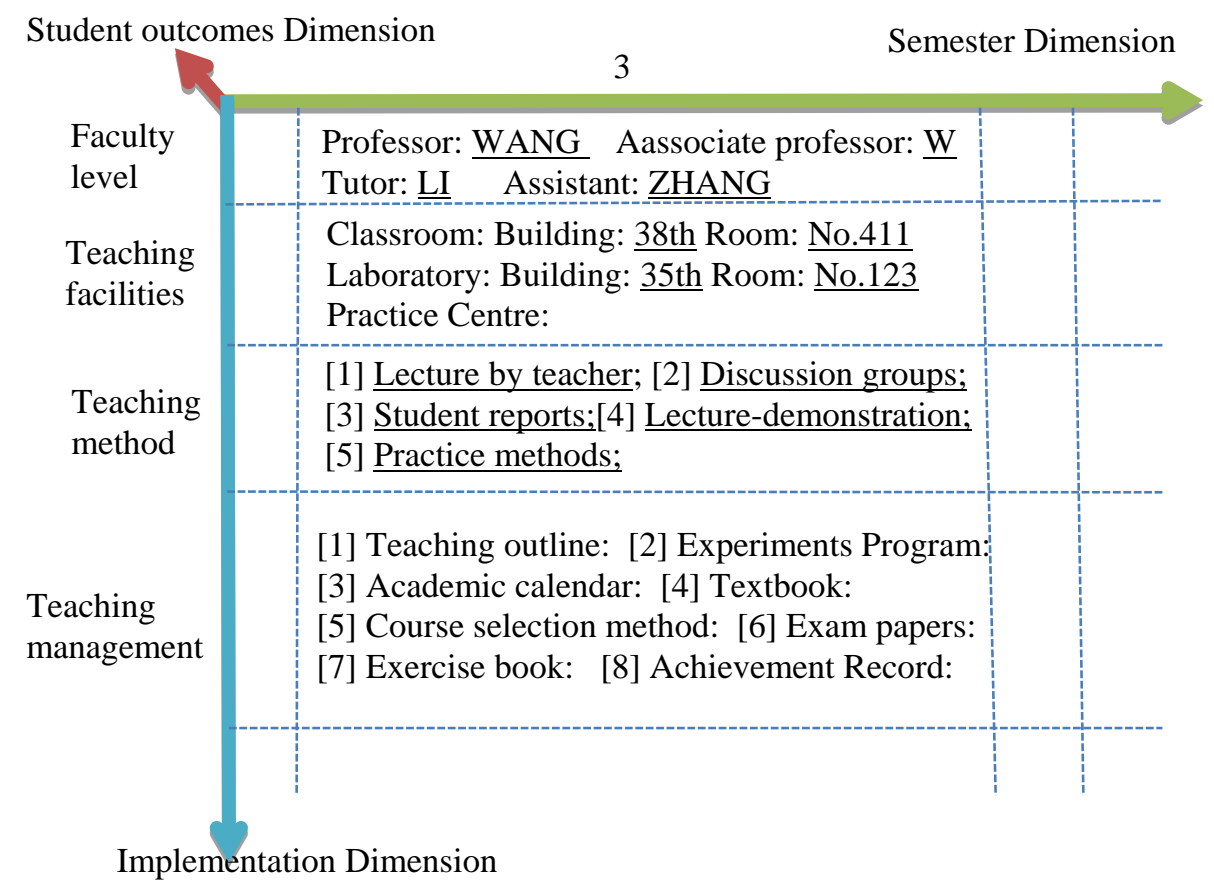

Fig. 4. Methodology space for Signal and system.

\section{Acknowledgement}

We would like to express our sincere thanks for the valuable suggestions and comments made by the reviewers and the support of the southwest university (Grant No. 60971016, No.SWFZ20150012).

\section{References}

[1] Barrow, R., \& Milburn, G, A critical dictionary of educational concepts. New York: Harvester Wheatsheaf, 1990.

[2] Edward S. Ebert II, Christine Ebert, Michael L. Bentley, The Educator's Field Guide: From Organization to Assessment (And Everything in Between), Corwin press, 2011.

[3] John Gorgone, Gordon B. Davis, Joseph S. Valacich, Heikki Topi, David L. Feinstein, and Herbert E. Longenecker, Model Curriculum and Guidelines for Undergraduate Degree Programs in Information Systems. Communications of the Association for Information Systems, vol.11, pp.1-65, 2012.

[4] Farid J. Sabongi, M.Arch., CID, MAI, Associate AIA, The Integration of BIM in the Undergraduate Curriculum: an analysis of undergraduate courses. Proceedings of the 45th ASC Annual Conference, pp.1-4, 2009.

[5] Xu bin, Study on the construction of undergraduate curriculum system for innovative engineering education, Tianjin University, 2010.

[6] Baumgartner and Venkataramanan, Actively linking learning outcomes and competencies to course design and delivery: Experiences from an undergraduate Information Systems program in Singapore. 2013 IEEE Global Engineering Education Conference (EDUCON), pp.13-15, 2013.

[7] Jim Gleeson, The European Credit Transfer System and curriculum design: product before process? Studies in Higher Education, vol.38, pp.921-938, 2013. 
[8] Tara Fenwick and Richard Edwards, Networks of knowledge, matters of learning, and criticality in higher education. Higher Education, vol.67, pp.35-50, 2014.

[9] Gerlach Christina, Mai Sandra, Schmidtmann Irene, Massen Clara, Reinholz Ulrike, Laufenberg-Feldmann Rita, and Weber Martin, Does Interdisciplinary and Multiprofessional Undergraduate Education Increase Students' Self-Confidence and Knowledge Toward Palliative Care? Evaluation of an Undergraduate Curriculum Design for Palliative Care at a German Academic Hospital, Journal of Palliative Medicine, vol.18, pp.513-519, 2015.

[10]Qing-Hua Deng, Artde Donald Kin-Tak Lam,Guo, A study on the reform orientation of undergraduate curriculum of digital media arts. 2016 International Conference on Applied System Innovation, pp.26-30, 2016.

[11]Gary M. Muir, Mission-driven, Manageable and Meaningful Assessment of an Undergraduate Neuroscience Program. J Undergrad Neurosci Educ. Vol.13, pp. A198-A205, 2015.

[12][ABET, Criteria for Accrediting Engineering Programs, 2016-2017.

http://www.abet.org/accreditation/accreditation-criteria/criteria-for-accrediting-engineering-p rograms-2016-2017/

[13] A. D. Hall, III, Three-dimensional morphology of systems engineering, IEEE Trans. Syst., Man, Cybern. vol. SMC-5, pp. 156-160, 1969. 